\title{
Reproductive seasonality in domestic sows kept outdoors without boars
}

\author{
J. M. Bassett, C. J. Bray*, and C. E. Sharpe \\ Growth and Development Unit, University of Oxford, University Field Laboratory, Wytham, \\ Oxford OX2 8QJ, UK
}

\begin{abstract}
Plasma progesterone, LH and prolactin concentrations were measured twice a week in mature sows kept outdoors without boars in two experiments to examine whether perception of daylength change underlies seasonal infertility in domestic pigs. In Expt 1, melatonin implants inserted on 12 April or 22 May to block perception of the increasing daylength did not affect the oestrous cycle significantly, since only two untreated control sows became seasonally anoestrous. In Expt 2, all control sows became anoestrous for $131 \pm 42.5$ days $(n=11)$. Melatonin implants inserted at the spring equinox $(n=9)$ prevented seasonal anoestrus $(P<0.001)$, but timed daily oral melatonin administration was less effective $(P<0.05)$ : 5 of 11 sows became anoestrous for $132 \pm 45.6$ days. In both experiments, there were significant low-amplitude seasonal rhythms in mean plasma prolactin and LH concentrations. Prolactin reached maximum concentra-
\end{abstract}

tions 2-4 weeks before the summer solstice, whereas LH reached a nadir 4-6 weeks after the summer solstice. Neither anoestrus nor melatonin administration altered these patterns consistently. Endogenous plasma melatonin was higher $(P<0.001)$ during darkness $\left(12.5 \mathrm{ng} \mathrm{l}^{-1}\right)$ than during daytime (8.9 $\left.\mathrm{ng} \mathrm{l}^{-1}\right)$ in untreated sows, but only clearly so during spring and summer. Melatonin implants increased mean daily plasma melatonin to $146 \mathrm{ng} \mathrm{l}^{-1}$, whereas melatonin fed at $15: 00 \mathrm{~h}$ increased values to 40-60 $\mathrm{ng} \mathrm{l}^{-1}$ 2-4 $\mathrm{h}$ after administration, but daytime concentrations were unchanged. Melatonin administration, despite decreasing seasonal anoestrus, did not prevent the seasonal increase in plasma prolactin and had no significant effect on plasma $\mathbf{L H}$; therefore, its role in regulating seasonal changes in the reproduction of domestic sows remains uncertain.

\section{Introduction}

Modern sows in commercial herds are expected to breed successfully throughout the year under a wide range of husbandry conditions. However, a decline of $10-25 \%$ in their reproductive efficiency during the summer months remains a commercial problem for the pig industry worldwide, whether sows are kept indoors (Love et al., 1993) or outdoors (Bray et al., 1994). It is still not known whether a common physiological regulatory mechanism underlies all manifestations of seasonal infertility in domestic pigs, but seasonal changes in duration of the daily photoperiod have been implicated as a common determinant (Claus and Weiler, 1985, 1987). Studies indicate that the seasonal characteristics of European wild boars (Sus scrofa) (Mauget, 1982, 1985; Delcroix et al., 1990) remain in modern domestic sows, with seasonal anoestrus occurring in some sows after the summer solstice (Claus et al., 1987). Reversal of the seasonal pattern of daylength change prevents the delay in onset of puberty observed during summer when gilts are kept without boars (Paterson and Pearce, 1990), as well as reversing seasonal changes in

Email: john.bassett@obs-gyn.ox.ac.uk

*Present address: Clinical Trial Service Unit, University of Oxford, Radcliffe Infirmary, Oxford OX2 6HE reproductive activity, blood testosterone and unconjugated oestrogens in adult boars (Claus and Weiler, 1987). Increasing the daily photoperiod before the summer solstice evidently regulates seasonal changes in fertility of the sow, but results of studies on the effects of photoperiod on pituitary gonadotrophin production are inconsistent (Love et al.,1993). A distinct annual cycle in plasma prolactin has been observed in males and female wild boars (Ravault et al., 1982), but seasonal changes in domestic pigs are more equivocal. Mechanisms by which photoperiodic information is transduced in domestic pigs remain uncertain. In other mammals that are seasonal breeders, the duration of the nocturnal increase in plasma melatonin concentration transduces seasonal information to neural systems regulating pituitary gonadotrophin secretion (Arendt, 1995). A low amplitude diurnal rhythm of plasma melatonin, entrained to the light-dark cycle, has been observed in prepubertal gilts (Paterson et al., 1992a) and administration of exogenous melatonin can be used to overcome the seasonal delay in onset of puberty observed in gilts. However, a robust diurnal rhythm of plasma melatonin has still to be demonstrated in adult sows, and the effects of melatonin on the reproductive seasonality of adult sows are unknown.

The aim of the present study was to investigate how season may regulate reproduction in adult domestic sows and to examine the possibility that some sows may be 
inherent seasonal breeders. Two experiments were set up to examine the hypothesis that seasonal regulation of reproduction in adult sows involves transduction of photoperiodic information via alterations in the daily rhythm of melatonin secretion. Sows that had already shown reduced fertility in summer were selected to increase the likelihood that they might be inherently seasonal. Oestrous cycle activity was studied in the absence of boars to maximize the possibility that any inherent tendency might be expressed. The presence of boars is known to mask much of the inhibitory effect of increasing daylength on attainment of puberty in gilts (Paterson and Pearce, 1990; Paterson et al., 1991) and boar pheromonal cues play an important role in maintaining regular oestrous cycles in sows (Booth and Signoret, 1992). Exogenous melatonin can be used to manipulate perception of photoperiodic change in other seasonal breeding species (Staples et al., 1991; Arendt, 1995) and therefore melatonin was administered to some of the sows in the present study to reduce the period when they could perceive increasing daylength.

Changes in oestrous cycle activity were determined throughout the annual cycle, monitored by measurement of plasma progesterone concentration in blood samples collected twice a week from sows kept outdoors without boars during two experiments. Observations are related to measurements of plasma $\mathrm{LH}$ and prolactin concentrations in the sows and to diurnal changes in plasma melatonin concentrations made at intervals during the year in the second experiment. A preliminary account of the work has been presented by Bassett et al. (1996).

\section{Materials and Methods}

\section{Animal accommodation and facilities}

All experimental work was carried out at the University of Oxford Field Station, Wytham, Oxford, grid reference SP472097 $\left(51.7^{\circ} \mathrm{N}\right)$, between 1991 and 1993. Experimental protocols, blood sampling, catheter insertion and implant insertion procedures used in the studies were carried out in accordance with a project licence approved by the Home Office under the terms of the Animals (Scientific Procedures) Act 1986.

A 1.2 ha field on a gravel terrace was divided into three equal sized paddocks using electric fencing. Each paddock accommodated a group of 9-11 sows and contained a large water trough and two large dry sow huts bedded regularly with straw. From May to September a wallow, where pigs could coat themselves with mud, was provided adjacent to the water trough. In addition, each group was provided with a shaded area using sheets of fine-mesh black nylon netting secured to four vertical $2 \mathrm{~m}$ long metal poles attached to the huts. All three paddocks opened, via gates, into a purposebuilt pen in which individual sows could be restrained to allow procedures such as blood sampling or administration of melatonin implants to take place. Throughout these experiments there were other pigs of both sexes in buildings
$200 \mathrm{~m}$ from the field, but none was greater than 6 months old (that is, there was neither physical nor olfactory contact between any of the experimental sows and mature boars). On occasion, it was necessary to remove sows from the field for short periods of time, either to recover from leg injuries, or for experiments to investigate diurnal variation in plasma hormone concentrations. Lame sows were kept in straw yards without artificial lighting, whereas those cannulated for intensive investigation were housed in standard farrowing crates in a building with transparent Perspex panels in the roof and walls that allowed natural light to enter. On overcast days in autumn, the amount of light ranged from 125 to 600 lux $50 \mathrm{~cm}$ above the floor, but was much higher on clear days.

\section{Experimental animals}

The mature sows used in these experiments, Camborough 'Blue' (Large White $\times$ Wessex Saddleback) or Camborough 'Line 12' (Landrace $\times$ Duroc) hybrid line sows bred specifically for use outdoors by the Pig Improvement Company (PIC, Fyfield Wick, Abingdon, Oxon), were obtained from large outdoor pig breeding units that were members of a farmers' cooperative (Thames Valley Pigs Ltd, Wallingford, Oxon). Where possible, sows with a history of previous seasonal infertility were selected for study and, throughout the study, their husbandry was maintained as similar as possible to that of sows on commercial units.

In Expt 1, all the sows came from a single large outdoor unit, 16 had an extended period of anoestrus after weaning, or had failed to conceive at the first oestrus after weaning during the summer of 1990, while six of the other 14 had a weaning-to-conception interval (WTCI) longer than 10 days. After selection, these sows (mean parity 3.8) were kept in yards at the breeding unit under natural daylight until they were transported to Wytham on 5 March 1991. Twenty sows were 'Blues' and the remainder 'Line 12' hybrids. For Expt 2, sows considered for selection had all failed to conceive successfully after being put to the boar after weaning during the summer of 1991 and were about to be culled barren. Blood samples were collected from each sow by jugular venepuncture twice a week for 3 weeks soon after the negative pregnancy test to establish whether sows were undergoing oestrous cycles at this time. A pattern of four high and two low progesterone concentrations in these samples was accepted as confirmation of an oestrous cycle. Thirty-three cyclic sows were selected and held at Wytham under natural daylight until February 1992. Five sows were 'Blues', the others were 'Line 12' hybrids. For both experiments, sows were distributed among three similar groups. They were then released into outdoor paddocks. Feeding regimens did not differ among groups in either study.

\section{Feeding}

Sows in the paddocks were fed each morning, by distributing sow biscuits or rolls directly onto the ground. 
The amount fed to each sow was adjusted to maintain sows in a satisfactory body condition, within the range $2.5-3.5 \mathrm{~kg}$ day $^{-1}$ per sow. In practice, sows were fed $3.0 \mathrm{~kg}^{\text {day }}{ }^{-1}$ in spring and autumn, $2.5 \mathrm{~kg} \mathrm{day}^{-1}$ in summer and $3.5 \mathrm{~kg}$ day $^{-1}$ during winter. In Expt 1, sows were fed biscuits containing 16\% crude protein (CP) and 13.0 MJ digestible energy (DE) kg-1 dry weight (Greenlands sow 16", Lys Mill, Watlington, Oxon). In Expt 2, sows were fed 'rolls' (14\% crude protein, $12.9 \mathrm{MJ} \mathrm{DE} \mathrm{kg}^{-1}$ dry weight) (Dry sow rolls, Lys Mill). Half a kilogramme of the daily rations per sow was given at 15:00 $\mathrm{h}$ between the spring and autumn equinoxes to permit oral administration of melatonin.

\section{Experimental treatments}

Expt 1 set out to examine the hypothesis that insertion of melatonin implants soon after the spring equinox (to increase the plasma melatonin concentration of a sow throughout the day to a value higher than peak concentrations of endogenous melatonin) would prevent any seasonal decline in parameters of reproductive efficiency by masking diurnal changes in endogenous secretion and thus perception of the increase in the duration of the daily photoperiod (Fig. 1a). In Group T1, each sow was administered implants of $180 \mathrm{mg}$ melatonin on 12 April. A further $180 \mathrm{mg}$ melatonin was administered on 4 July, 12 weeks later. In Group T2 sows, administration of melatonin implants was delayed until 22 May (that is, 6 weeks later than Group T1 sows and 1 month before the summer solstice) to examine whether duration of exposure to increasing daylength might be important. A further $180 \mathrm{mg}$ melatonin was administered on 9 August. Sows in the control group (Group C) received no exogenous melatonin.

In Expt 2, the same hypothesis was re-examined, but the sows used had been culled barren after mating during the previous summer. In this experiment, effects on oestrous cyclicity and plasma hormone concentrations of sows given melatonin implants $(180 \mathrm{mg})$, inserted s.c. at the spring equinox (22 March 1992) and again on 4 September (Group $\mathrm{MI})$, were compared with measurements on untreated control sows (Group C) and with those on sows in a third group (Group MD) fed $5 \mathrm{mg}$ melatonin daily at approximately 15:00 h from 22 March until 21 September 1992, since it had been reported that timed oral administration of melatonin to gilts, to simulate a long night pattern of plasma melatonin, was more efficacious than implants in overcoming the delayed onset of puberty (Paterson et al., 1992b). The postulated effects of these treatments on perception of daylight by the sows are illustrated (Fig. 1b).

\section{Melatonin administration}

At implantation, ten Regulin ${ }^{\circledR}$ implants, each containing 18 mg melatonin (batch number GR90520/E; Hoechst Animal Health, Milton Keynes), were inserted s.c. in the neck of sows behind the left ear using a Regulin ${ }^{\circledR}$ implanter gun (Hoechst Animal Health). The number of implants inserted was determined by the need to maintain a stable plasma melatonin concentration above the endogenous range over a period of 3 months and was based on advice from the supplier. Implants were placed individually in a radial pattern from a single puncture in the skin via the $2.5 \mathrm{~cm}$ long needle supplied with the implanter gun. Sows were administered implants on the left side to minimize the possibility of sampling from veins into which the implant may be draining when collecting blood samples, either by venepuncture or via a cannula on the right side. Sows used in Expt 1 were not weighed, but the mean weight of sows at the start of Expt 2 was $218 \mathrm{~kg}$, therefore ten Regulin ${ }^{\circledR}$ implants represented a dose of approximately $826 \mu \mathrm{g}$ melatonin $\mathrm{kg}^{-1}$ live weight. For oral administration of melatonin, $0.5 \mathrm{~kg}$ batches of sow rolls were treated with $5 \mathrm{mg}$ of melatonin using a method similar to published methods (Kennaway and Seamark, 1980; Diekman et al., 1991a; Paterson et al., 1992b). Fresh solutions of melatonin (Sigma Chemical Company Ltd, Poole, Dorset) in absolute ethanol (James Burrough (FAD) Ltd, Witham, Essex) were prepared weekly. The $0.5 \mathrm{~kg}$ of this food was fed daily at 15:00 h, using a row of individual sow feeders at the edge of the paddock to ensure sows in Group MD received equal amounts of melatonin. Sows in the other two groups were fed $0.5 \mathrm{~kg}$ of untreated food on the ground at the same time. Melatonin feeding commenced on 22 March 1992 and continued until 21 September 1992. Each sow in Group MD consumed $910 \mathrm{mg}$ melatonin at a rate of approximately $22 \mu \mathrm{g} \mathrm{kg}{ }^{-1}$ live weight day ${ }^{-1}$ during the 6 months over which they received this diet.

\section{Blood sampling}

Blood samples $(10 \mathrm{ml})$ were collected by jugular venepuncture into heparinized syringes twice a week from every sow in Expt 1 from 15 April until 9 December 1991, but sampling of two sows was continued until 10 January 1992. In Expt 2, samples were collected twice a week from each sow from 28 February 1992 until 25 February 1993. Samples were transferred to stoppered plastic tubes kept on ice. Plasma was separated by centrifugation at $2000 \mathrm{~g}$ for $15 \mathrm{~min}$ at $4^{\circ} \mathrm{C}$ within $2 \mathrm{~h}$ of sample collection and stored at $-20^{\circ} \mathrm{C}$

Up to six sows from each of the groups in Expt 2 were removed from the paddock to an adjacent building on six occasions during the year to investigate seasonal effects on diurnal variation in plasma concentrations of melatonin, $\mathrm{LH}$ and prolactin and to assess the effects of experimental treatment on these patterns. Each group was studied separately within a period of 21 days. Sows were held in farrowing crates for up to $72 \mathrm{~h}$ for vascular cannulation and repeated blood sample collection over $25 \mathrm{~h}$ commencing on the day after cannulation. The method of cannulation was adapted from descriptions by Peacock (1991) and Smith and Ficken (1991) and was usually performed on the right side of the neck, since this was more convenient, as well as being contralateral to the melatonin implants. No sow with melatonin implants was cannulated on the left 

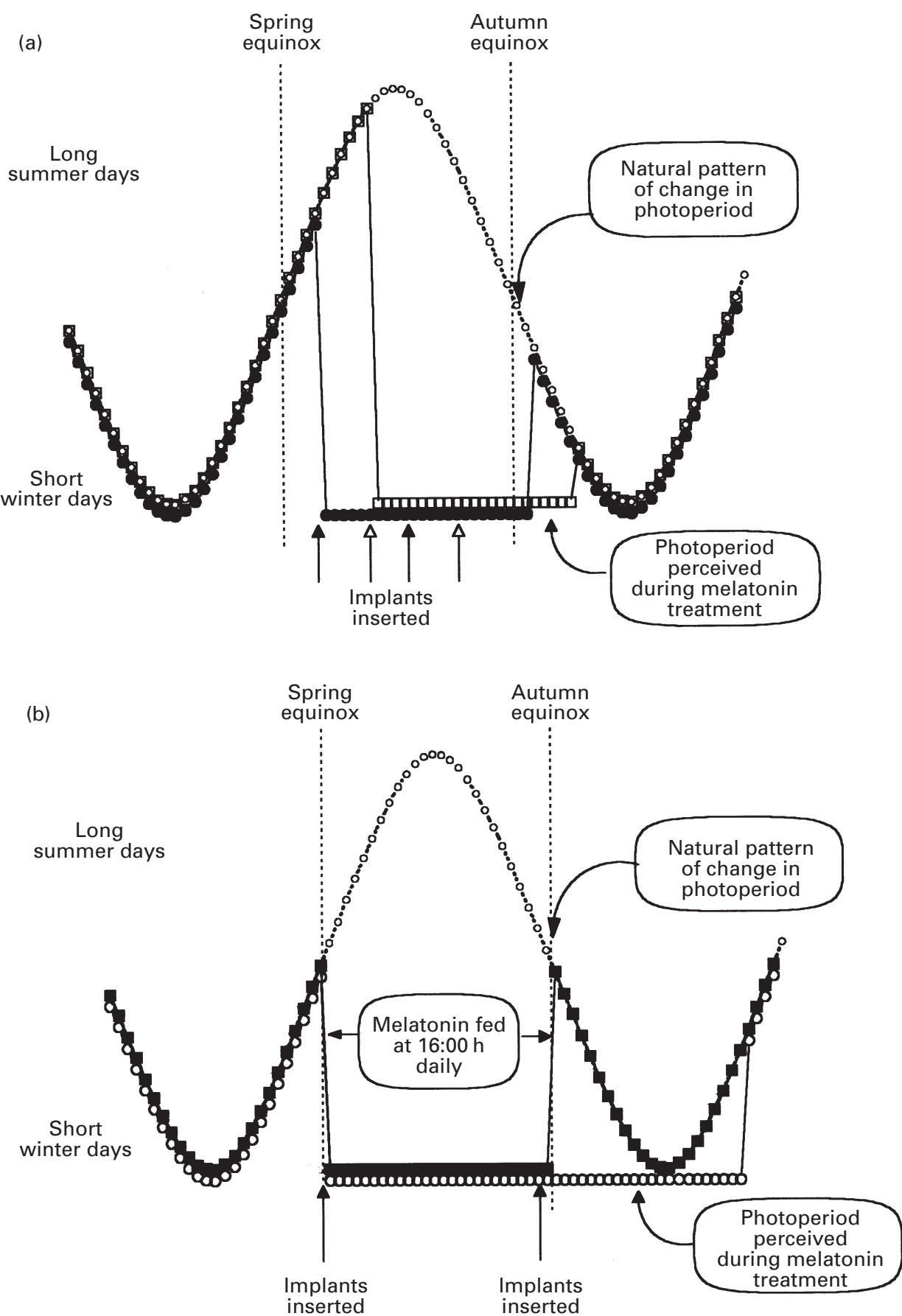

Fig. 1. Illustration of changes in duration of the perceived daily photoperiod that should result from melatonin administration to sows during Expts 1 (a) and 2 (b) if, as hypothesized, the continuous high plasma melatonin concentration provided by melatonin implants is perceived by the sow as a short-day photoperiod. In Expt 1, $180 \mathrm{mg}$ melatonin implants (ten Regulin ${ }^{\circledR}$ implants, each containing $18 \mathrm{mg}$ melatonin) were inserted s.c. into the neck of sows early in April (Group T1: -) or late in May (Group T2, $\square$ ) and again 12 weeks later. In Expt 2, similar melatonin implants were inserted s.c. into one group of sows at the spring equinox and again during August (Group MI, O). In another group, $5 \mathrm{mg}$ melatonin was administered by admixture with food given daily at 15:00 $\mathrm{h}$ between the spring and autumn equinoxes (Group MD, $\mathbf{\square}$ ). Untreated control sows experienced only natural changes in the duration of the daily photoperiod at Oxford illustrated by the open symbols and dotted line. 
side of the neck. Blood samples $(10 \mathrm{ml})$ were obtained from the cannula every hour for $25 \mathrm{~h}$ starting at 09:00 $\mathrm{h}$ on the next day. Additional samples were obtained at $30 \mathrm{~min}$ intervals around dusk and dawn. The procedure was repeated at intervals of 2 months to encompass the full range of natural daylength.

\section{Hormone analyses}

Progesterone. Plasma concentrations of progesterone were determined by radioimmunoassay using an antiserum raised in sheep against progesterone-3-CMO conjugated to keyhole limpet haemocyanin (ILS Ltd, London) and $[1,2,6,7-3 \mathrm{H}]$ progesterone (Amersham International, Amersham, Bucks). Aliquots of plasma $(100 \mu \mathrm{l})$ were extracted twice with $1.5 \mathrm{ml}$ petroleum ether. After evaporation to dryness under $\mathrm{N}_{2}$, combined extracts were redissolved in $50 \mu \mathrm{l}$ of assay buffer at $4^{\circ} \mathrm{C}$ overnight, before incubation with antibody and labelled tracer. Antibody-bound and free steroid were separated by centrifugation at $2000 \mathrm{~g}$ at $4{ }^{\circ} \mathrm{C}$ for 15 min after addition of $500 \mu \mathrm{l}$ of a $0.125 \%$ (w/v) charcoal suspension. Pooled plasma samples were included in each assay. Intra- and inter-assay coefficients of variation were 13.5 and $17.8 \%$ at $10 \mathrm{nmol} \mathrm{I}^{-1}$, and 11.1 and $14.7 \%$ at $25 \mathrm{nmol} \mathrm{I}^{-1}$, respectively. Mean assay sensitivity (percentage bound with no hormone present $-2 \mathrm{SD}$ ) was $3 \mathrm{nmol}$ $\mathrm{I}^{-1}$ plasma. The mean $\pm \mathrm{SE}$ recovery of tritiated progesterone added to plasma samples extracted by this method was $77.4 \pm 2.3 \%(n=10)$. The plasma samples collected twice a week from the sows were assayed at regular intervals throughout each study to monitor the occurrence of oestrous cycles, rather than to assess seasonal changes in the plasma concentration of progesterone during the luteal phase of the oestrous cycles.

$\mathrm{LH}$ and prolactin. Plasma $\mathrm{LH}$ and prolactin concentrations were determined by homologous radioimmunoassays using anti-pig LH antiserum (AFP-1111779) and anti-pig prolactin antiserum (AFP-084255) provided by A. H. Parlow (Pituitary Hormones and Antisera Center, Harbor UCLA Medical Center, Torrance, CA) and highly purified pig LH (AFP-10714B) and pig prolactin (AFP9764B) preparations provided by $S$. Raiiti through the University of Maryland School of Medicine, National Hormone and Pituitary Program of the National Institute of Diabetes and Digestive and Kidney Diseases, National Institutes of Health. The sensitivity of the LH assay was $0.05 \mu \mathrm{g} \mathrm{I}^{-1}$ and intra- and inter-assay coefficients of variation at $0.230 \mu \mathrm{g} \mathrm{I}^{-1}$ were 9.5 and $13.8 \%$, respectively. The sensitivity of the prolactin assay was $0.4 \mu \mathrm{g} \mathrm{I}^{-1}$ and intra-

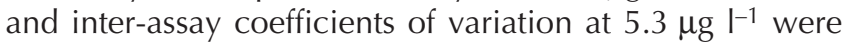
6.7 and $13.3 \%$, respectively. All samples collected twice a week from an individual sow were included in the same assay to minimize confounding of inter-animal and interassay variability.

Melatonin. Plasma concentrations of melatonin were determined by a direct radioimmunoassay using the same Prospect 6A antiserum and method used by Paterson et al. (1992a) with some modification. The antiserum (kindly provided by A. Foldes, CSIRO Prospect, NSW) was used at a dilution of 1:100,000 and melatonin standards were prepared in assay buffer, rather than in daytime pig plasma. Separation of antibody-bound and free-labelled melatonin was carried out using 0.2\% charcoal:0.02\% (w/v) dextran in assay buffer. Appropriate volumes of pooled pig plasma collected during daytime or assay buffer were added $15 \mathrm{~min}$ before addition of the charcoal suspension to equalize the plasma concentration of all tubes. Intra- and inter-assay coefficients of variation were 13.7 and $17.7 \%$ at $13.3 \mathrm{ng} \mathrm{I}^{-1}$, and were 14.3 and $16.1 \%$ at $224 \mathrm{ng} \mathrm{l}^{-1}$, respectively. Mean assay sensitivity was $3.7 \mathrm{ng} \mathrm{^{-1 }}$. No melatonin results are presented for Expt 1, as there was insufficient plasma for reanalysis of samples assayed originally with a different sheep anti-melatonin antiserum (Stockgrand Ltd, University of Surrey, Guildford, Surrey) using a procedure based on that described by Fraser et al. (1983). This assay was found unsatisfactory for direct assay of pig plasma and, with this method, high concentrations of melatonin were observed frequently in daytime plasma samples from sows not treated with exogenous melatonin. The authenticity of these high values was investigated by assaying five samples of daytime plasma, with concentrations determined by the Stockgrand method, ranging from 10 to $280 \mathrm{ng} \mathrm{I}^{-1}$ and a mean of $91 \pm 109 \mathrm{ng} \mathrm{I}^{-1}$, by A. Lewy using gas chromatographymass spectrometry (GC-MS). This method yielded values ranging from 4.8 to $13.8 \mathrm{ng} \mathrm{I}^{-1}$ with a mean of $9.8 \pm$ $13.8 \mathrm{ng} \mathrm{I}^{-1}$. Klupiec et al. (1997) also showed that nonspecific interference from unidentified components of plasma invalidated melatonin measurement by direct radioimmunoassay in pig plasma.

\section{Calculations}

Effects of treatment and season on plasma concentrations of $\mathrm{LH}$ and prolactin in both experiments were assessed by comparison of mean values over successive 3 week periods, calculated from averages of measurements made twice a week on each sow, as marked variations in hormone concentration occur during each 21 day oestrous cycle. Since behavioural oestrus was not determined, endocrine profiles for oestrous cycles in individual sows were aligned using the rapid decline in plasma progesterone concentration associated with onset of luteolysis to assess how LH and prolactin concentrations at specific stages within the oestrous cycle were influenced by season or experimental treatment. Some refinement was achieved subsequently by alignment of prolactin and LH peak values during luteolysis and the follicular phase. Therefore, all samples for each cycle included in the analysis are dated relative to the time that the LH peak value occurred after luteolysis and the presumptive day of oestrus. Because the number of observations included in mean values for single days varied considerably, average concentrations of $\mathrm{LH}$, prolactin and progesterone during four 
defined stages of the cycle were calculated for each animal before statistical assessment of treatment, or seasonal, effects on hormone concentration. These stages were: (1) early luteal phase (days 18-13 before oestrus); (2) late luteal phase (days 12-7 before oestrus); (3) luteolysis and the follicular phase (days $6-3$ before oestrus); and (4) peri-oestrus phase (from day 2 before to day 1 after oestrus).

Ratios of LH:prolactin and its inverse were calculated for each of these stages from ratios in individual samples. Average values for each individual sow were calculated using all cycles occurring in the season to examine seasonal influences on $\mathrm{LH}$ and prolactin concentrations during these four stages. Seasons were defined as those in which oestrus occurred between the spring equinox and summer solstice (spring), the summer solstice and autumn equinox (summer), the autumn equinox and winter solstice (autumn) and the winter solstice and spring equinox (winter). Mean values for this period include only sows from Expt 2.

It is necessary to collect samples at intervals of 15 or 20 min to define LH pulsatility adequately (Diekman et al., 1991b). However, preliminary examination of LH concentrations in samples collected hourly for $25 \mathrm{~h}$ during the present investigation indicated that $\mathrm{LH}$ secretory pulses were of relatively low frequency and measurable amplitude throughout the luteal phase of the oestrous cycle and during anoestrus. Therefore, it seemed possible that the samples collected every hour, together with the additional 4-6 samples collected around sunset and sunrise could be used to provide some information about LH pulsatility at some stages of the oestrous cycle during the $24 \mathrm{~h}$ serial blood sampling studies carried out in Expt 2. The stage of the oestrous cycle of each sow on each occasion was determined retrospectively as described above. Fifty-two sample series were from sows in the luteal phase (28 early luteal and 24 late-luteal sows) and a further 19 were from sows that were anoestrus at the time of repeated sampling. Samples within $1 \mathrm{SD}$ of the overall mean for the series were identified to calculate a basal value for LH concentration throughout the day in these series. Peak samples for individual secretory pulses were then identified graphically, counted and the amplitude of each peak calculated by subtraction of the basal mean from the peak value. The peak value had to be $>2 \mathrm{SD}$ above the basal mean and, where possible, should have had another value in the peak $>2$ SD above the basal mean to be considered a secretory pulse. As calculations were carried out after logarithmic transformation, the exponent of the pulse amplitude was used as a measure of the multiplicative increase above basal concentration in each pulse, rather than an absolute increase in concentration. No attempt was made to determine the number or amplitude of $\mathrm{LH}$ pulses during either follicular or peri-oestrous phases of the cycle, because of the low sampling frequency. Preliminary investigations indicated that the sampling frequency was too low to attempt assessment of prolactin pulsatility at any stage of the oestrous cycle. However, mean LH and prolactin concentrations of samples collected during the light and dark phases of the day were calculated for all sows in these studies.

\section{Statistical analyses}

The statistical significance of differences among treatment groups in the frequency of seasonal anoestrus and in the total number of oestrous cycles for each sow during Expt 2 was determined using the Kruskal-Wallis nonparametric ANOVA to avoid assumptions about the distribution of these parameters. A probability of $<0.05$ was considered significant.

All plasma hormone concentrations were converted to natural logarithms before calculation of averages, group means or other statistical procedures. Therefore, mean values presented in the text and tables are geometric means, with values as natural logarithms \pm SEM below the geometric mean where appropriate. For graphical presentation, geometric means \pm SEM values are presented using multiplicative scales. For presentation of seasonal changes in 3 week mean values of $\mathrm{LH}$ and prolactin, curves were fitted to the data using the equation $y=a^{*} \cos \left(b^{*} x\right)+c$ and the iterative curve fitting routine of Fig.P for Windows 2.9 (Biosoft, Cambridge). The initial value for $b$ was chosen so that the period of the function would approximate 1 year.

Multivariate GLM ANOVA procedures for unequal subclass numbers or repeated measures GLM ANOVA procedures, as appropriate, were used to examine the statistical significance of treatment, season and experiment effects on plasma concentrations of $\mathrm{LH}$, prolactin and melatonin. The absence or occurrence of seasonal anoestrus was included as a factor in analyses of 3 week period means, or the seasonal means for each of the four oestrous cycle stages, defined above to evaluate whether $\mathrm{LH}$ and prolactin concentrations in sows that exhibited seasonal anoestrus differed from those of sows that had continuous cycles. Within experiment, 3 week mean LH and prolactin concentrations were regarded as repeated measures in the analyses. Because of the variable occurrence and duration of seasonal anoestrus and the different sampling periods of the two experiments, stage of cycle was the only variable that could be included as a repeated measure in analyses to examine effects of experiment, treatment and season on $\mathrm{LH}$ and prolactin concentrations within the cycle. However, a modified Bonferroni calculation of $t$ was used for assessment of statistical significance. In these analyses, probability values $<0.02$ were regarded as significant, otherwise, values $<0.05$ were considered significant. Observations on all sows not receiving melatonin at the time of the observations were included in analyses of diurnal changes in endogenous plasma melatonin concentrations in the sows. SPSS for Windows 7.5 was used for all statistical procedures.

\section{Results}

\section{Selection of sows for experiment}

Despite the stated intention of selecting sows with a previous history of reproductive seasonality, the WTCl of the 30 sows available for study in Expt 1 ranged from 3 to 70 

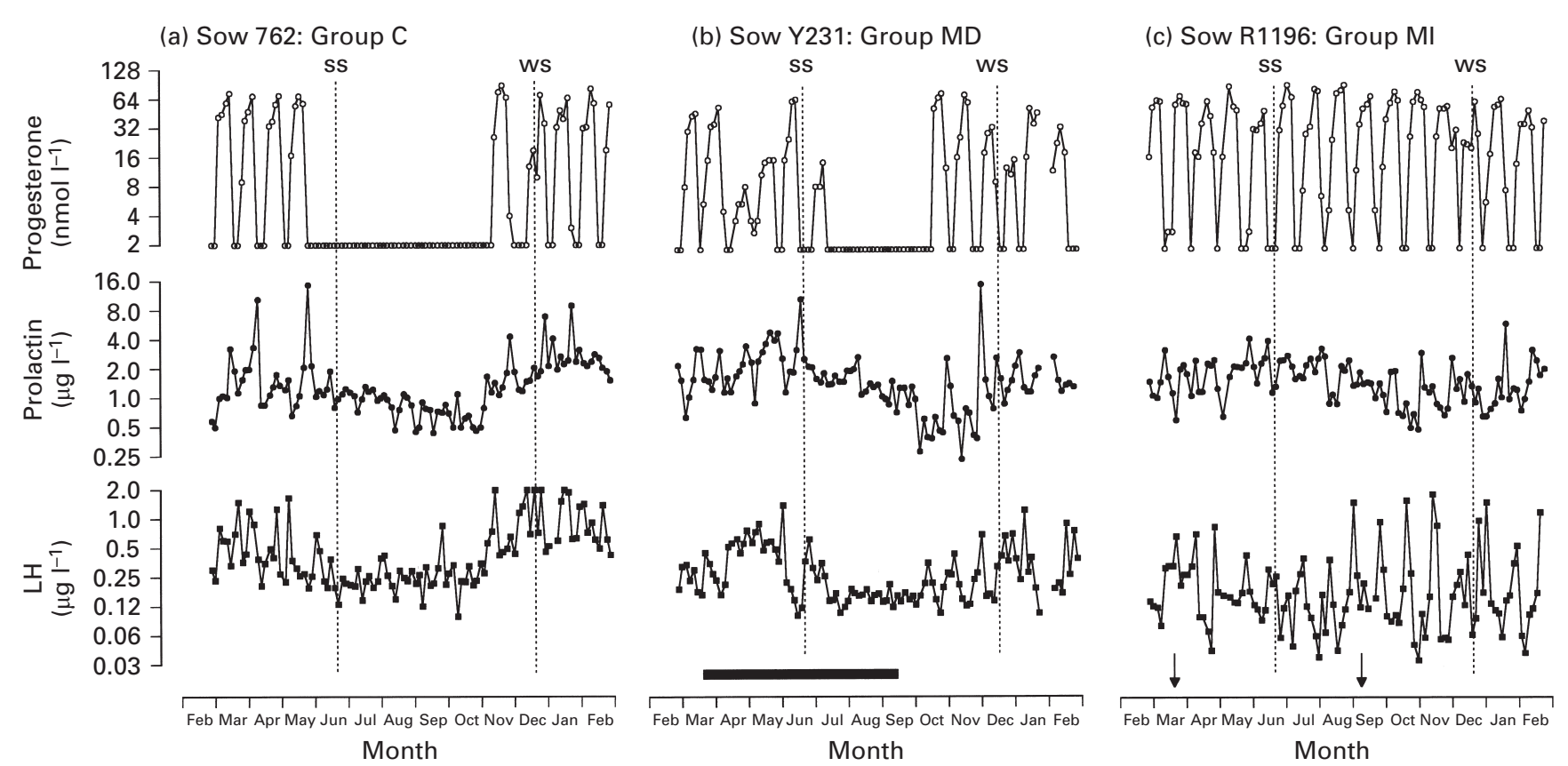

Fig. 2. Changes throughout the year in plasma progesterone, prolactin and LH concentrations in an untreated control sow from control Group C (a), a sow from Group MD (b), fed 5 mg melatonin daily at 15:00 h between the spring and autumn equinox ( $\square$ ) and a sow from Group MI (c) given $180 \mathrm{mg}$ melatonin implants on 22 March and again on 9 September (indicated by vertical arrows) during Expt 2. Times of summer (SS) and winter (WS) solstices are shown by the vertical dashed lines on each panel.

days in the 28 cases for which both dates were known. The WTCl was prolonged (70 days) in only one sow. Thirteen sows had conceived at their first post-weaning oestrus and the $\mathrm{WTCl}$ was $9.7 \pm 5.7$ days (mean $\pm \mathrm{SD}$ ). The other 14 sows either failed to conceive at their first post-weaning oestrus, or had a short period of anoestrus and a mean WTCI of $31.5 \pm 5.7$ days. In contrast, all 33 sows chosen for Expt 2 had been culled barren in the autumn of 1991. Each sow had been weaned and put to the boar between 11 June and 15 August 1991 (median = 14 July 1991) and had a mean parity of 3.4 (range $1-7$ ). All were undergoing oestrous cycles after removal from the herd.

\section{Health of sows}

There were no major health problems during either experiment and blood samples were obtained twice a week from most sows. Two sows with melatonin implants were withdrawn from Group $\mathrm{T} 1$ in Expt 1 because they were pregnant, having conceived when accidentally put with a group of boars shortly before transport to Wytham. Two sows also had to be removed from Group MI during Expt 2: one because it failed to show oestrous cycles, and another because of a severe foot infection that failed to respond to treatment.

\section{Patterns of oestrous cycles}

Blood sample collection twice a week and measurement of plasma progesterone was effective in monitoring the occurrence of oestrous cycles during both experiments and also permitted easy recognition that there were long-term seasonal changes in plasma concentrations of $\mathrm{LH}$ and prolactin, despite short-term changes of larger magnitude in both hormones within each oestrous cycle (Fig. 2).

All 28 sows in Expt 1 were undergoing oestrous cycles at the start of the study and 22 continued to cycle without interruption, including all eight sows in Group T1, six sows from Group T2 and eight untreated control sows (Table 1). However, periods of temporary anoestrus, when the plasma progesterone concentration was undetectable for more than three consecutive samples, were observed in six sows. The onset of anoestrus occurred within a period of $<4$ weeks from 20 June to 16 July 1991 in all six, but its duration varied greatly (Table 1). In the two sows from Group C, the duration of anoestrus was prolonged, lasting 21 weeks, with oestrous cycles resuming only at the beginning of December. In the other sows, all from Group T2, anoestrus was relatively short, one sow missing only a single cycle and the other two missing three or four cycles. Because so few sows became anoestrous, or had irregular cycles, there were no significant differences among the groups. Melatonin administration had no significant influence on the pattern of oestrous cycle activity in this experiment.

In Expt 2, by contrast, there were highly significant differences $(P>0.001)$ among treatment groups in the frequency with which seasonal anoestrus occurred and in the total number of oestrous cycles observed over the 12 months during which blood samples were collected (Table 1). 
Table 1. Number of oestrous cycles and the occurrence of seasonal anoestrus in sows kept outdoors during Expts 1 and 2

\begin{tabular}{lccc}
\hline & $\begin{array}{c}\text { Mean } \pm \text { SEM } \\
\text { frequency } \\
\text { of anoestrus }\end{array}$ & $\begin{array}{c}\text { Mean } \pm \text { SEM } \\
\text { anoestrus (days) }(n)\end{array}$ & $\begin{array}{c}\text { number of } \\
\text { oestrous cycles }(n)\end{array}$ \\
\hline $\begin{array}{l}\text { Expt 1 } \\
\text { Group C }\end{array}$ & & \\
Group EM & $2 / 10$ & $05 \pm 2.8(2)$ & $9.7 \pm 2.79(10)$ \\
Group LM & $0 / 8$ & $50 \pm 25.7(3)$ & $11.0 \pm 0.00(8)$ \\
Expt 2 & $3 / 10$ & $131 \pm 42.5(11)$ & $11.3 \pm 2.20(11)^{\mathrm{a}}$ \\
Group C & & $132 \pm 45.6(5)$ & $13.8 \pm 3.34(11)^{\mathrm{b}}$ \\
Group MD & $11 / 11^{\mathrm{a}}$ & 0 & $16.4 \pm 0.88(9)^{\mathrm{b}}$ \\
Group MI & $5 / 11^{\mathrm{b}}$ & $0 / 9^{\mathrm{c}}$ & $0.48(9)$ \\
\hline
\end{tabular}

Expt 1 lasted for 238 days, from 15 April to 9 December 1991; Expt 2 lasted for 366 days, from 28 February 1992 to 28 February 1993.

For each experiment, values with different superscripts in the same column are significantly different $(P<0.05)$.

All sows in Group C became anoestrous during the summer. The frequency of summer anoestrus was significantly reduced in groups administered melatonin, either as implants, or orally at 15:00 h daily. Seasonal anoestrus was totally absent in Group Ml given melatonin implants $(P<0.001)$ and the mean number of oestrous cycles observed was significantly greater $(P<0.001)$. Oral administration of melatonin to Group MD sows was less effective $(P<0.05)$ in preventing seasonal anoestrus. Nevertheless, the frequency with which anoestrus occurred in Group MD was significantly lower $(P<0.05)$ than it was in Group $C$, whether assessed by the absence of cyclic activity during the summer, or by the total number of cycles observed. The duration of seasonal anoestrus ranged from 9 to 29 weeks (mean 18.7 weeks) in Group C. Anoestrus commenced between 10 April and 28 August 1992 and ended with a highly synchronized resumption of cyclic activity between 30 October and 5 November 1992. Only one sow showed evidence of anoestrus outside this period (Table 1). The duration of anoestrus in the five sows from Group MD which became anoestrus for a period in the summer was similar to that in group C (Table 1) and ranged from 13 to 29 weeks, but only one had a seasonal pattern similar to that of Group C sows.

\section{Factors influencing plasma prolactin and $\mathrm{LH}$ concentrations during the experiments}

It was necessary to average values over an entire cycle, or else confine comparisons to particular stages of the oestrous cycle, to evaluate effects of season and experimental treatment on concentrations of $\mathrm{LH}$ and prolactin, because of the large magnitude of multiplicative increases in plasma concentrations of both hormones during the follicular phase of the cycle that were readily evident in the samples collected twice a week from most sows (Fig. 2). When mean values over 3 weeks for all sows were plotted against time, similar low amplitude seasonal rhythms in plasma concentrations of $\mathrm{LH}$ and prolactin were evident during both experiments (Fig. 3). Rhythms for the two hormones were distinct, yet consistent, over the 2 years of study. Curves fitted to the relationship of each hormone with date (Fig. 3), accounted for over $80 \%$ of the variance among mean values over 3 weeks for both prolactin and $\mathrm{LH}$. Seasonal maxima for LH occurred in February and minima occurred in August during both years, while prolactin concentration was highest in late May and lowest during late November. Multivariate ANOVA confirmed that 3 week mean values of both $\mathrm{LH}$ and prolactin around the time of the seasonal maximum differed significantly $(P<0.001)$ from those around the seasonal minimum. There was no significant influence of melatonin administration, or of seasonal anoestrus, on the concentration of either hormone, but interactions between period and melatonin treatment were significant in both years and interactions of period with anoestrus were significant during 1992. There was no evidence that melatonin administration prevented the seasonal increase in prolactin concentration. Indeed, prolactin concentrations of melatonin-treated sows in Expt 2 were higher than those of control sows, but this may have been due to confounding of treatment and seasonal anoestrus effects, since the mean prolactin concentration of anoestrous sows $\left(1.47 \mu \mathrm{g} \mathrm{I}^{-1}\right)$ was significantly lower $(P<0.01)$ than that of sows that were cyclic throughout the year $\left(2.24 \mu \mathrm{g} \mathrm{I}^{-1}\right)$.

Calculation of mean prolactin and LH concentrations for four stages of the oestrous cycle from values in individual sows during the two experiments confirmed their recognized patterns of change within the cycle (Table 2). In summer, the geometric mean $\mathrm{LH}$ concentration throughout the cycle $\left(0.27 \mu \mathrm{g} \mathrm{I}^{-1}\right)$ was significantly less $(P<0.001)$ than it was in winter $\left(0.43 \mu \mathrm{g} \mathrm{I}^{-1}\right)$, while the mean prolactin concentration in summer $\left(2.76 \mu \mathrm{g} \mathrm{I}^{-1}\right)$ was significantly greater $(P<0.001)$ than it was in autumn $\left(1.46 \mu \mathrm{g} \mathrm{I}^{-1}\right)$ or winter $\left(1.52 \mu \mathrm{g} \mathrm{l}^{-1}\right)$. This seasonal effect occurred in both experiments, but was most readily seen during Expt 2, in 

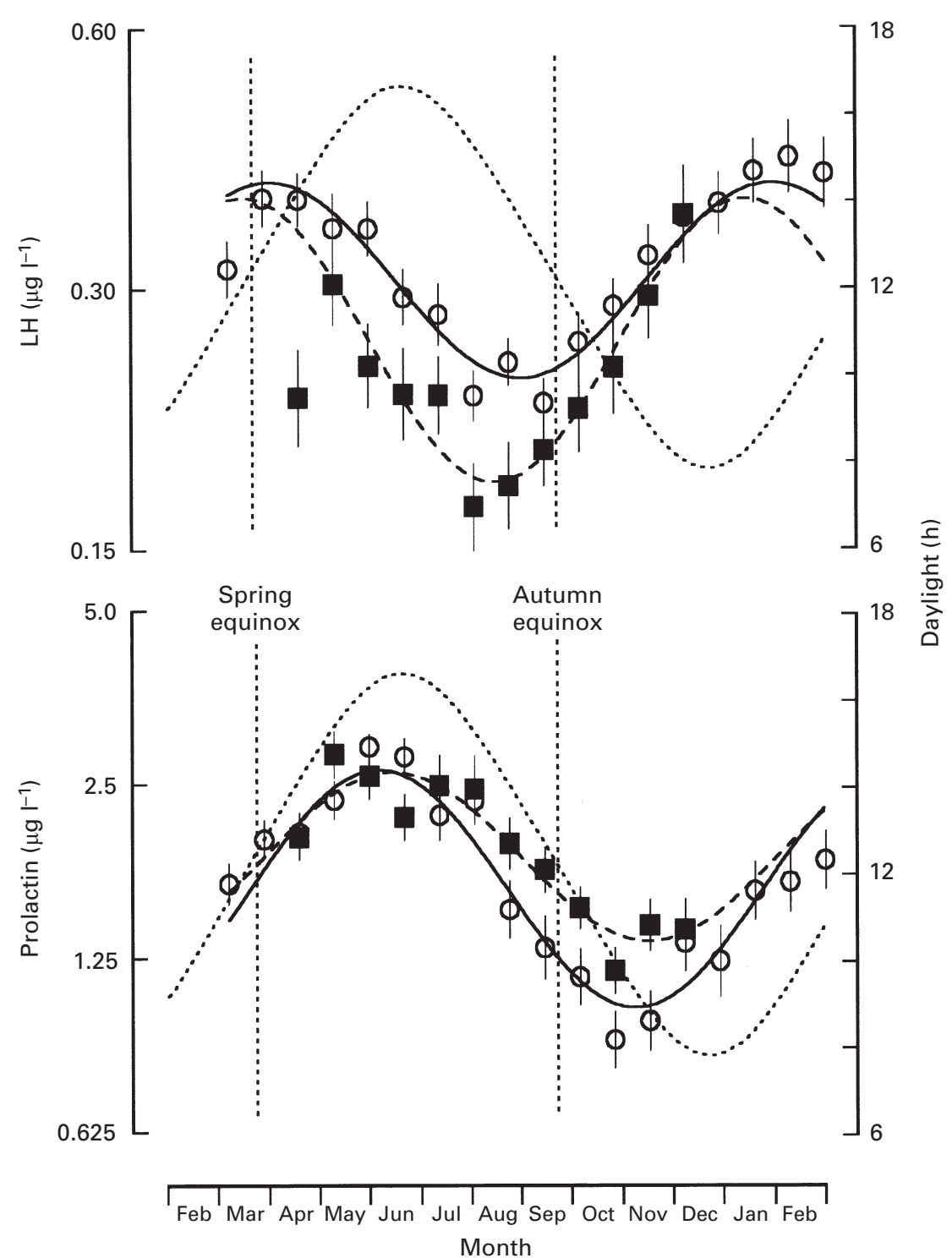

Fig. 3. Geometric mean \pm SEM plasma LH and prolactin concentrations for all sows in Expt $1(\boldsymbol{\square} ; n=28)$ and Expt $2(\mathrm{O} ; n=31)$. The relationships of $\mathrm{LH}$ and prolactin with date, calculated iteratively using the formula $y=a^{*} \cos \left(b^{*} x\right)+c$ are shown (Expt 1: ----; Expt 2:-). Changes in the duration of daylight at Oxford throughout the year (...).

which LH concentrations in summer were 2-4-fold less throughout the cycle than in winter, relative to those of prolactin, because of their different seasonal rhythms (Fig. 4). Mean values for spring and autumn were intermediate between those for summer and winter, but are not shown for reasons of clarity. During seasonal anoestrus, plasma LH concentrations of sows (Table 2) were comparable to luteal phase values of cyclic sows during summer, but prolactin concentrations were similar to those of cyclic sows during the early luteal phase in autumn $\left(1.07 \mu \mathrm{g} \mathrm{l}^{-1}\right)$. Before onset of anoestrus, prolactin concentrations in the late luteal phase $\left(1.79 \mu \mathrm{g} \mathrm{l}^{-1}\right)$ and at luteolysis $\left(2.26 \mu \mathrm{g} \mathrm{I}^{-1}\right)$ during the last cycle were both significantly lower $(P<0.05)$ than they were in the previous cycle $\left(2.53 \mu \mathrm{g} \mathrm{I}^{-1}\right.$ and $4.27 \mu \mathrm{g} \mathrm{I}^{-1}$, respectively; $n=20$ ), with virtually no evidence of a peak value associated with luteolysis. Plasma $\mathrm{LH}$ concentration during the peri-oestrus period $\left(0.29 \mu \mathrm{gl}^{-1}\right.$ versus $\left.0.60 \mu \mathrm{gl}^{-1}\right)$ was also significantly lower $(P<0.01)$ than it was in the previous cycle. Consistent with these differences, the amplitude of curves fitted to the seasonal oscillations in LH and prolactin in sows that became anoestrous tended to be greater than those observed in sows that were continuously cyclic throughout the year. The nadir in plasma LH concentration and initiation of a new phase of increased plasma LH during the autumn occurred a month earlier in sows that were continuously cyclic than in sows that became anoestrus, but the timing of maxima and minima for curves fitted to plasma prolactin values differed by $<2$ weeks. 
Table 2. Influence of oestrous cycle stage on mean plasma LH and prolactin concentrations in adult sows kept outdoors without boars

\begin{tabular}{|c|c|c|c|c|c|}
\hline & \multicolumn{4}{|c|}{ Stage of cycle* } & \multirow[b]{2}{*}{ Anoestrus $^{\dagger}$} \\
\hline & Early luteal & Late luteal & Early follicular & Pre- oestrus & \\
\hline \multirow[t]{2}{*}{ Prolactin $\left(\mu \mathrm{g}^{-1}\right)$} & $1.44^{\mathrm{a}}$ & $1.82^{\mathrm{b}}$ & $3.54^{\mathrm{c}}$ & $1.96^{\mathrm{d}}$ & 1.10 \\
\hline & $036 \pm 0.038$ & $0.60 \pm 0.037$ & $1.26 \pm 0.057$ & $0.68 \pm 0.038$ & $0.09 \pm 0.105$ \\
\hline \multirow[t]{2}{*}{ Plasma LH (ng..$\left.^{-1}\right)$} & $281^{\mathrm{a}}$ & $226^{b}$ & $306^{c}$ & $634^{d}$ & 222 \\
\hline & $5.64 \pm 0.036$ & $5.42 \pm 0.039$ & $5.72 \pm 0.029$ & $6.45 \pm 0.051$ & $5.40 \pm 0.112$ \\
\hline
\end{tabular}

*Geometric mean concentrations throughout the year in 648 oestrous cycles from 59 sows during Expts 1 and 2 . Values are estimated marginal means, together with the natural logarithm \pm SEM value beneath.

${ }^{\dagger}$ Geometric means of average concentrations, as logarithms, in twice-weekly samples from 20 sows throughout the period of seasonal anoestrus in Expts 1 and 2 .

Values with a different superscript differ significantly $(P<0.02)$.

Diurnal changes in plasma $\mathrm{LH}$ concentrations of sows on six occasions throughout the year in Expt 2 did not provide any clarification of the mechanism by which seasonal changes in plasma LH are brought about. There were insufficient numbers of sows from each group in the luteal phase of the cycle at the time at which repeated sampling took place to permit a proper analysis of treatment or seasonal effects on the pulsatile release of LH. However, during the cycles monitored, the frequency of LH pulses in the early luteal phase $(6.5 \pm 0.34$ pulses per $24 \mathrm{~h} ; n=28)$ was significantly greater $(P<0.02)$ than it was in the late luteal phase $(4.7 \pm 0.41$ pulses per $24 \mathrm{~h} ; n=24)$, while pulse amplitude, expressed as a multiplicative increase over the basal concentration, was greater $(P<0.02)$ in the late luteal phase (3.53-fold; $\operatorname{Ln} 1.26 \pm 0.117)$ than it was in the early luteal phase (2.37-fold; Ln $0.86 \pm 0.098)$. ANOVA did not identify any significant effect of season or treatment on the value of either measure of LH pulsatility. During summer, pulse frequency and the amplitude of the increase above baseline were $6.8 \pm 0.76$ pulses per $24 \mathrm{~h}(n=9)$ and 2.3 -fold ( $\operatorname{Ln} 0.83 \pm 0.13$ ) in the early luteal phase and were $4.9 \pm 0.40$ pulses per $24 \mathrm{~h}(n=7)$ and 2.7-fold ( $\mathrm{Ln}$ $1.01 \pm 0.21$ ) during the late luteal phase, respectively, in sows that continued to be cyclic. However, seasonal and treatment effects could be confounded since all control sows sampled during summer were anoestrous. LH pulse frequency (6.2 \pm 0.51 pulses per $24 \mathrm{~h} ; n=19$ ) and amplitude (2.53-fold; Ln $0.93 \pm 0.147)$ in anoestrous sows were similar to values in early luteal sows, but differences from late luteal values were not significant. Sampling frequency was too low for examination of $\mathrm{LH}$ secretion characteristics at other cycle stages. However, mean plasma concentrations of $\mathrm{LH}(0.38 \mu \mathrm{g}$ $\left.\mathrm{I}^{-1}\right)$ and prolactin $\left(337 \mu \mathrm{g} \mathrm{I}^{-1}\right)$ at night were both significantly higher $(P<0.001)$ than those during daylight hours $(1.42$ and $302 \mu \mathrm{g} \mathrm{I}^{-1}$, respectively), although differences were small.

\section{Effects of exogenous melatonin administration on plasma melatonin concentration}

Melatonin concentrations of plasma samples collected during daytime from sows in Expt 1 are not reported because of specificity problems with the assay method. In
Expt 2, melatonin concentrations of control sows, measured by direct radioimmunoassy, were in the same range as values determined by GC-MS. Geometric mean plasma melatonin concentrations of samples collected during the morning at 2 week intervals between the spring and autumn equinoxes from Group $\mathrm{C}$ sows were $6.1 \mathrm{ng}$ melatonin $\mathrm{I}^{-1}$ $(\mathrm{Ln}=1.81 \pm 0.038)$. In Group MD sows fed melatonin at 15:00 h each day, plasma concentrations were $8.3 \mathrm{ng}$ melatonin $\mathrm{I}^{-1}(\mathrm{Ln}=2.12 \pm 0.060)$ and in Group Ml sows with s.c. melatonin implants, the plasma concentration was 146 ng melatonin $\mathrm{I}^{-1}(\mathrm{Ln}=4.98 \pm 0.044)$. Measurement of diurnal changes in plasma melatonin on six occasions during the year showed that Group MI sows had functional implants throughout the study; their plasma melatonin concentration remaining some tenfold or more greater than that of endogenous melatonin in control sows after implant insertion (Fig. 5). In Group MD, daily oral administration of melatonin at 15:00 $\mathrm{h}$ between the spring and autumn equinoxes increased plasma melatonin well before the onset of darkness and to a greater degree than the nocturnal increase in endogenous melatonin concentration observed in these sows on the two occasions after the autumn equinox when melatonin was not fed. Nevertheless, after melatonin feeding, the duration of the increase in melatonin concentration above daytime values was comparable to that of the nocturnal increase in endogenous melatonin observed in these sows during autumn and winter (Fig. 5).

\section{Effects of season on diurnal changes in plasma concentrations of endogenous melatonin}

Hourly mean plasma concentrations of endogenous melatonin in all sows not currently receiving exogenous melatonin are shown (Fig. 6). Any nocturnal increase in plasma melatonin was far smaller than that achieved by dietary administration of melatonin to Group $\mathrm{MD}$ and varied in amplitude among the six occasions. Nevertheless, mean endogenous melatonin concentration during darkness $\left(12.5 \mathrm{ng} \mathrm{I}^{-1}\right.$; Ln $\left.2.52 \pm 0.028\right)$ was significantly greater $(P<0.001)$ than it was during daylight $\left(8.9 \mathrm{ng} \mathrm{I}^{-1} ; \mathrm{Ln}\right.$ $2.19 \pm 0.028$ ) when all studies were considered. Analysis of values before and after each photophase change confirmed 

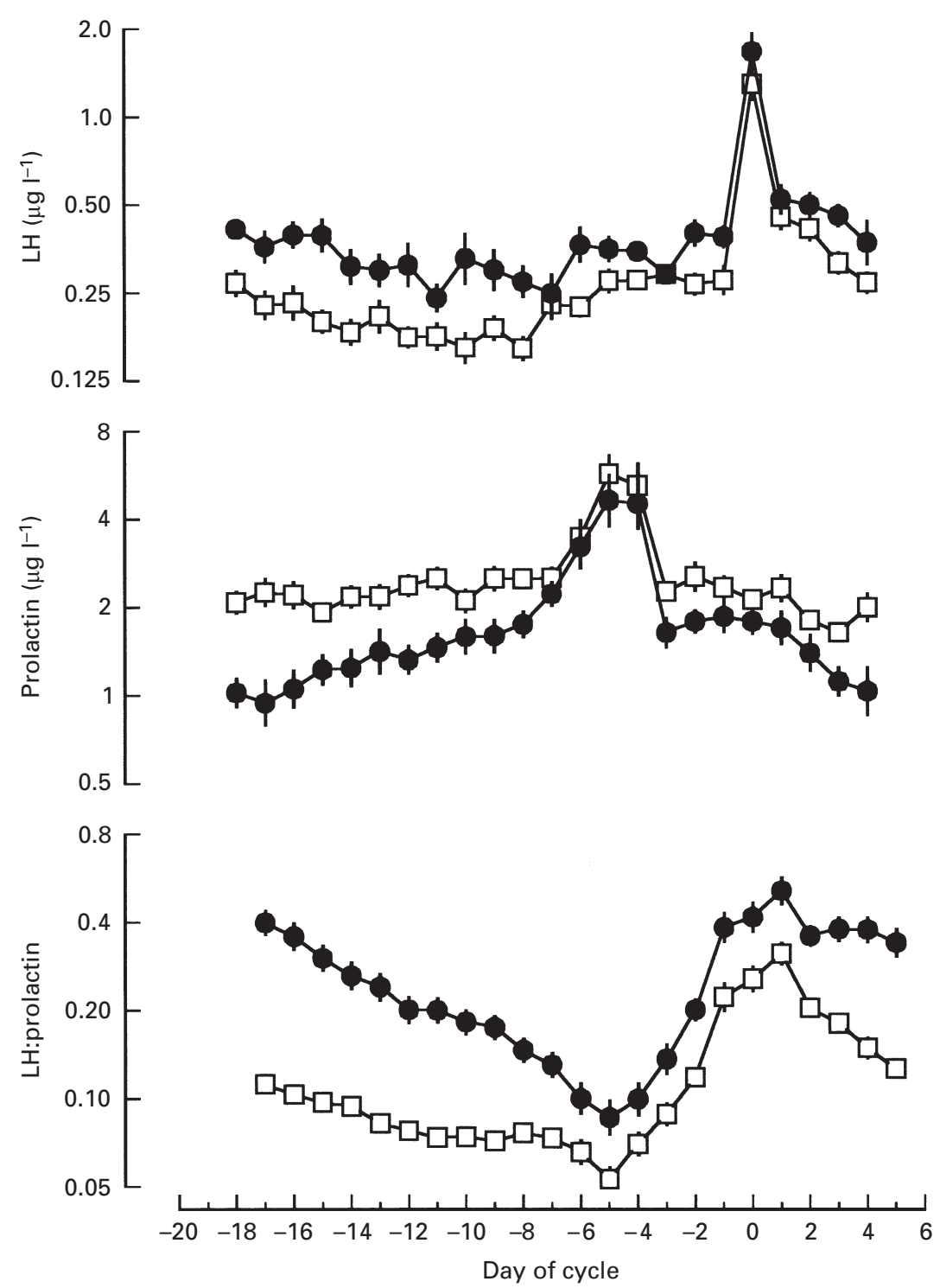

Fig. 4. Geometric mean \pm SEM plasma LH and prolactin concentrations over 3 weeks, and the ratio of $\mathrm{LH}$ :prolactin during composite oestrous cycles constructed from blood samples taken twice a week on adult sows kept outdoors without boars at Wytham, Oxfordshire during Expt 2. Cycles occurring during summer (July-Sept: $\square$; 68 cycles from 20 sows) and winter (Jan-Mar: $; 109$ cycles from 31 sows) were aligned before calculation of daily geometric mean concentrations.

that values during darkness were significantly $(P<0.001)$ higher than those during daylight and showed that the increase to nocturnal concentrations anticipated the onset of darkness slightly. In contrast, dawn was associated with a decrease in melatonin concentration to the lowest values of the day. The effect of season in these analyses was not significant, but a significant season $\times$ phase interaction indicated that the magnitude of the response varied with season. The concentration of endogenous melatonin during darkness was significantly greater $(P<0.02)$ on each of the four occasions studied during spring and summer. On the other two occasions, in October and December, endogenous melatonin concentration was also significantly greater $(P<0.05)$ during darkness in sows that had been fed melatonin at 15:00 $\mathrm{h}$ daily between the spring and autumn equinoxes (Fig. 5), but there was no significant difference between mean values for the two phases on either occasion in sows from the control group, so that, overall, values during darkness on these two occasions were not significantly increased (Fig. 6). 


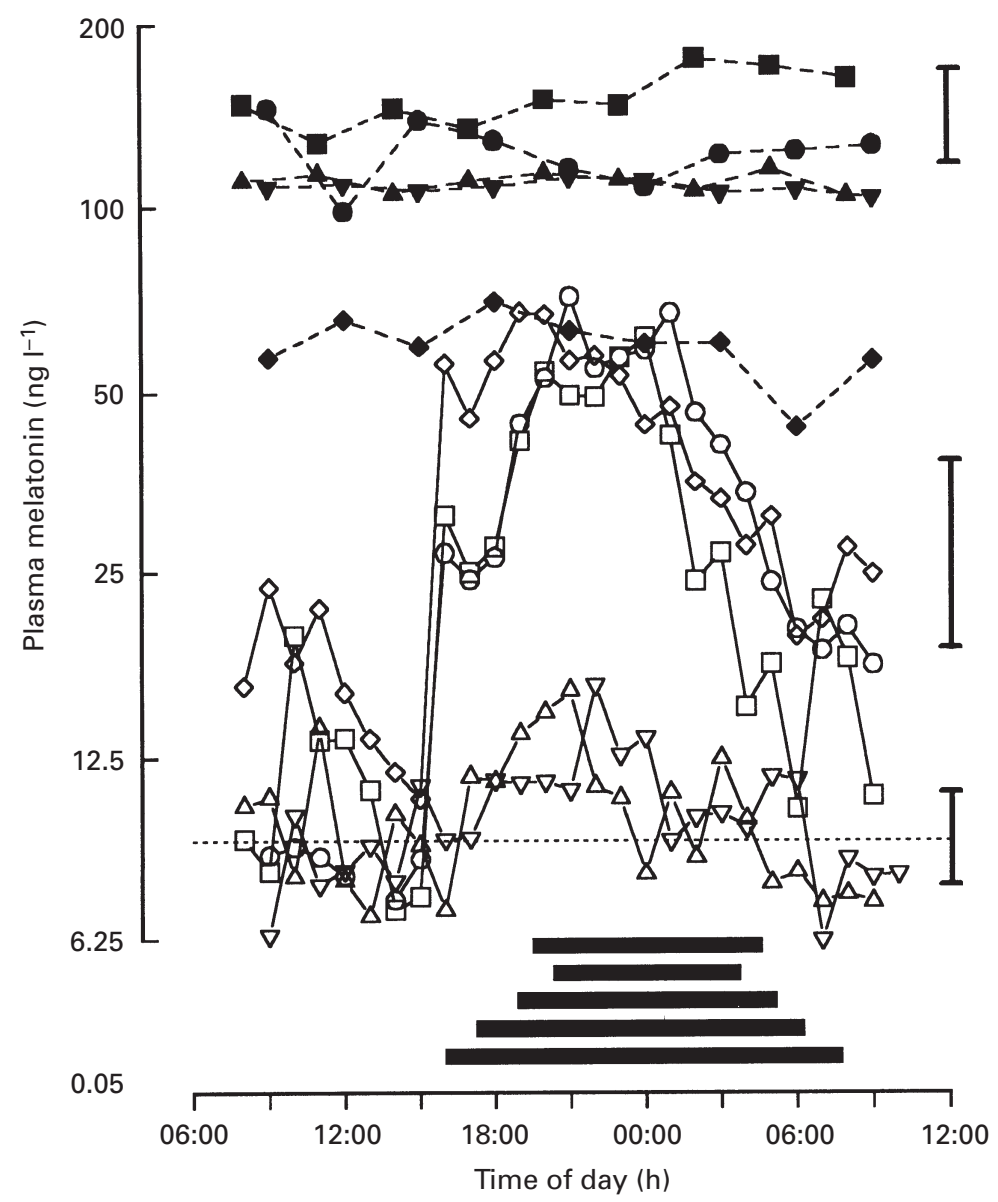

Fig. 5. Plasma melatonin concentrations throughout the day in Group MD sows (open symbols, solid lines) fed melatonin at 15:00 h daily between the spring and autumn equinoxes and in Group MI sows (solid symbols, dashed lines) given s.c. implants of melatonin (180 mg) on 22 March and again on 4 September during Expt 2. Values are mean \pm SEM of observations on four to six sows from each group on three occasions between the spring and autumn equinoxes (early May: $\bigcirc, 0$; late June: $\square, \boldsymbol{\square}$; late August: $\diamond, \diamond$ ) and on two further occasions after oral melatonin administration to Group MD sows had ceased (late October; $\triangle, \mathbf{\Delta}$; mid-December: $\nabla, \boldsymbol{\nabla}$ ). For clarity, only values every $3 \mathrm{~h}$ are shown for Group $\mathrm{Ml}$ sows. Filled bars show the period of darkness on each study occasion. The horizontal dotted line shows the mean melatonin concentration of Group C sows during daylight hours.

\section{Discussion}

The occurrence of seasonal anoestrus in a proportion of sows used in both experiments and the significant seasonal alterations in plasma $\mathrm{LH}$ and prolactin concentrations observed provide strong evidence that highly prolific modern hybrid sow lines retain elements of reproductive seasonality. The ability of melatonin implants, inserted at the spring equinox, to prevent seasonal anoestrus provides further support for the contention that the duration of the daily photoperiod is the primary determinant of this reproductive seasonality. Melatonin implants, inserted at or soon after the spring equinox, prevented the occurrence of seasonal anoestrus and maintained continuous oestrous cycles for the duration of the study, just as daily oral administration of melatonin at 15:00 $\mathrm{h}$ throughout the summer does in red deer hinds (Adam et al., 1989). This finding is in contrast to the situation in sheep, in which prolonged maintenance of a short-day photoperiod after the winter solstice, or its simulation by melatonin implants, fails to prolong the breeding season significantly (Malpaux et al., 1988). However, although the present study indicates that the perception of increasing daylength from the spring equinox to the summer solstice by sows was masked by melatonin administration, either as implants or daily feeding at 15:00 $\mathrm{h}$, the mechanism by which this masking 


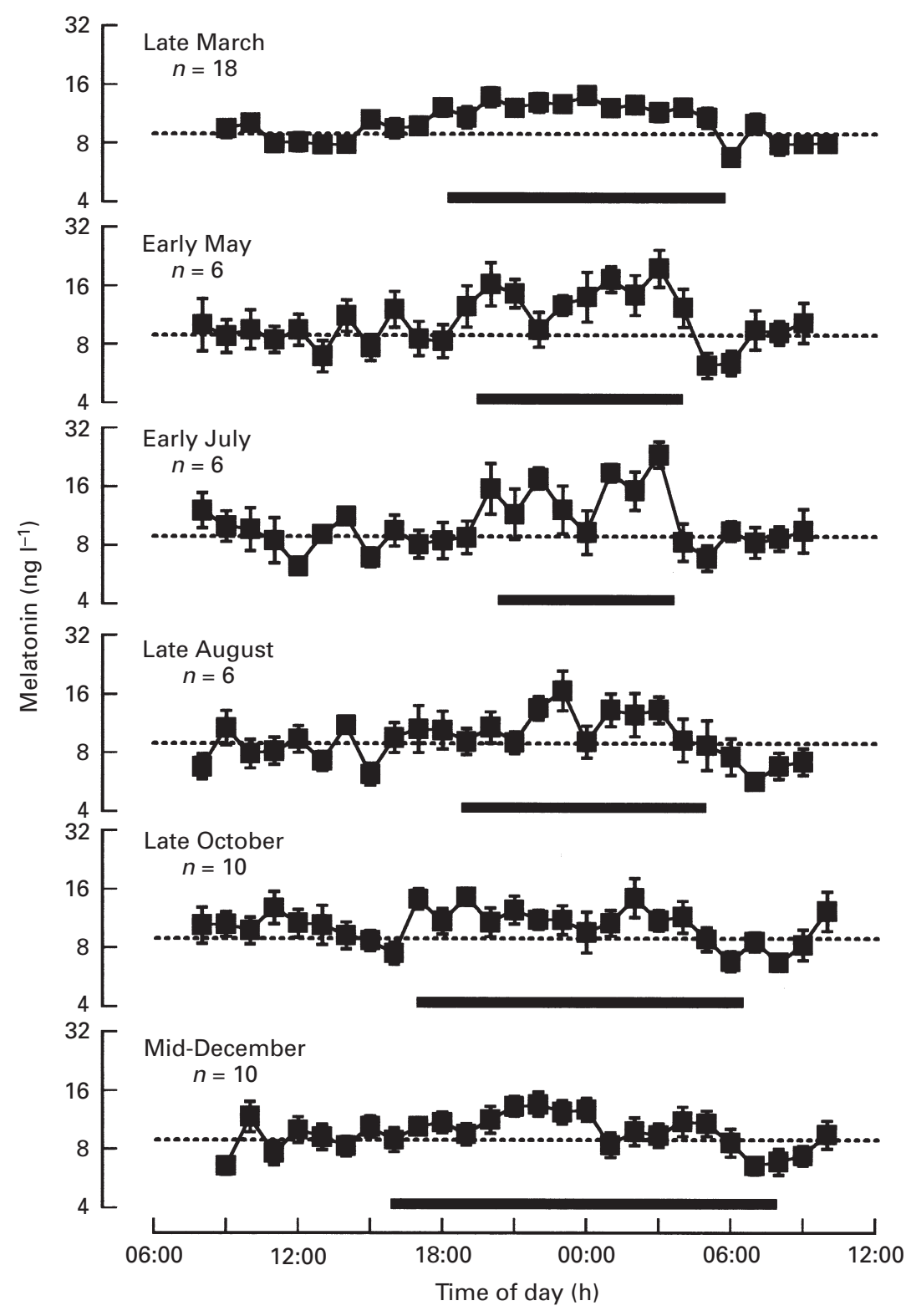

Fig. 6. Influence of seasonal changes in the duration of the daily photoperiod on geometric mean \pm SEM plasma melatonin concentrations throughout the day in control sows, together with sows from the other two groups on days when they were not administered melatonin in Expt 2. The horizontal bar indicates the period of darkness. Blood sampling commenced at 09:00 h on each occasion, but all sample times have been adjusted to time of day. The dotted horizontal line on each panel indicates the mean daytime melatonin concentration for all studies shown.

was achieved has not been established. Whether the signal provided by a constant high melatonin concentration is interpreted as a stimulatory winter short-day pattern promoting reproductive activity, as is the case in sheep (O'Callaghan et al., 1991), or merely blocks perception of the long-day pattern cannot be determined unequivocally from the present observations. Paterson et al. (1992a) showed that a short-day photoperiod resulted in an increased plasma melatonin concentration throughout the night in prepubertal gilts but, during autumn and winter in the present study, a significant increase in endogenous plasma melatonin related to the duration of darkness was observed only in adult sows that had received daily oral melatonin throughout the summer. No significant nocturnal increase in plasma melatonin was observed on these occasions in sows from the control group, so uncertainty remains about the short-day melatonin pattern and its significance for photoperiodic signalling in adult sows. 
In sheep, refractoriness to short days, or expression of an endogenous rhythm of reproduction, appears to terminate the breeding season (Malpaux et al., 1988). In red deer, by contrast, the end of the breeding season and onset of anoestrus is triggered by the inhibitory effects on gonadotrophin secretion of exposure to the short duration nocturnal increase in plasma melatonin occurring during long days (Adam et al., 1989). Therefore, the simplest interpretation of the present observations may be that an inhibitory long-day melatonin signal, provided by increasing daylength after the spring equinox, also triggers the end of the breeding season in adult sows. Prolonged maintenance of an increased melatonin concentration after implant insertion prevents perception of this inhibitory signal. Oral administration of melatonin at 15:00 h each day would likewise prevent perception of the inhibitory short-duration nocturnal increase in endogenous melatonin release observed in control sows during spring and early summer. This interpretation is consistent with the effectiveness of a decreasing light programme in preventing the delay in onset of puberty in gilts associated with increasing daylength (Paterson and Pearce, 1990). Reasons for the reduced efficacy of oral melatonin in the present study, or for differences between the present observations and those of Paterson et al. (1992b), who reported that oral melatonin prevented the seasonal delay in onset of puberty in gilts whereas implants were ineffective, are less obvious, since both oral melatonin and implants increased plasma melatonin to concentrations above the nocturnal range of endogenous melatonin over a period comparable to, or longer than, that of a short-day pattern or continuously in both studies. Whatever the reason, the explanation offered by Paterson et al. (1992b), that melatonin implants were ineffective because the constant high concentration of melatonin was interpreted as continuous darkness and inhibited reproductive activity, seems unlikely to be correct.

Plasma melatonin concentrations established by implants, or diurnal changes brought about by timed daily oral melatonin administration, greatly exceeded any changes in endogenous melatonin observed in the sows studied. However, in other species, it is the duration of the nocturnal increase in plasma melatonin concentration that is important; the amplitude of the increase does not appear to play a significant role, provided a threshold limit for physiological nocturnal concentrations is exceeded (Arendt, 1995). It should be appreciated that the dosage regimens chosen for the present study were based on information about suitable doses for sheep (Staples et al., 1991) and the very limited information available about endogenous melatonin concentrations in sows at the time experiments began early in 1991 (for review, see Paterson et al., 1992a). These measurements, like those of Paterson et al. (1992a) subsequently indicated that many earlier values reported may have been excessively high because direct immunoassay of melatonin in pig plasma with some antisera can be subject to nonspecific interference (Paterson and Foldes, 1994; Klupiec et al., 1997). Although the concentrations of endogenous melatonin measured in sows are very low, the present results, like those of Wyrzykowski et al. (1989) and Paterson et al. (1992a), are consistent with the belief that melatonin secretion is increased in sows during darkness and decreased during daylight, and that the duration of increased secretion during darkness is related to the duration of the night, despite a report that significant nocturnal increases in pineal $n$-acetyl transferase activity or melatonin concentration (Reiter et al., 1987) are absent in prepubertal pigs.

The distinct low-amplitude seasonal rhythms in plasma concentrations of both $\mathrm{LH}$ and prolactin observed in the present study are consistent with earlier studies of changes in $\mathrm{LH}$ and prolactin concentrations with season in domestic sows (Ravault et al., 1982; Armstrong et al., 1986). However, while photoperiodic manipulation and melatonin administration, which alter timing of the breeding season in sheep, are associated with large changes in the secretion and plasma concentrations of plasma LH and prolactin (Karsch et al., 1989; Woodfill et al., 1994), the onset of seasonal anoestrus in sows was not associated with a comparable large decrease in mean plasma $\mathrm{LH}$ concentration, whereas LH pulse frequency and amplitude remained comparable to those in sows in the early luteal phase of the cycle. However, mean plasma prolactin concentrations were in fact reduced. Although melatonin administration to sows in the present study largely prevented anoestrus and maintained regular oestrous cycles, it had no significant short- or long-term influence on plasma concentrations of either $\mathrm{LH}$ or prolactin during these cycles. Melatonin adminstration also had no significant effect on the characteristics of pulsatile LH release during the luteal phase of the oestrous cycle in the limited studies carried out. Perhaps no other effect on LH should be expected, since the observations of Robinson et al. (1991) in ewes showed that daily melatonin feeding at 15:00 $\mathrm{h}$ to advance the start of a new breeding season does not alter $\mathrm{LH}$ pulse frequency before initiation of the characteristic high frequency follicular phase pulse pattern associated with resumption of oestrous cycles $>60$ days after the start of treatment. Reversed patterns of photoperiodic change, which prevent the normal summer delay in attainment of puberty in gilts, prevent the associated delay in maturation of LH secretory profiles (Paterson et al., 1992a), but similar reversed patterns of photoperiodic change during gestation and lactation have no significant effect on LH secretory profiles or ovarian receptor populations in primiparous sows at the end of lactation (Kermabon et al., 1995). The seasonal oscillation in the mean plasma LH concentrations of sows exhibiting oestrous cycles implies the presence of an underlying annual rhythm of reproduction and seasonal influences on the regulation of $\mathrm{LH}$ release, but whether this annual rhythm is synchronized by exposure to long-day photoperiodic cues, as it is in sheep (Woodfill et al., 1994), or its timing can be advanced by exposure to a short-day melatonin pattern, cannot be determined from the present studies. 
One striking finding of the present study was that melatonin administration had no inhibitory effect on the magnitude of the small seasonal increase in plasma prolactin to its maximum before the summer solstice. This finding is in contrast to the situation in sheep and deer, in which provision of a short-day pattern of melatonin during spring or summer consistently prevents the much larger seasonal increase in plasma prolactin (Poulton et al., 1986; Adam et al., 1989). Melatonin receptors in the pars tuberalis of the pituitary mediate inhibitory effects of short daylength and of melatonin implants on the seasonal increase of prolactin in sheep (Lincoln and Clarke, 1994) but, although melatonin receptors have been observed in the pars tuberalis of neonatal pig pituitaries (Williams et al., 1999), functional inhibition of prolactin release via this pathway seems unlikely to be significant in adult sows.

The significance of the seasonal changes in relative concentrations of $\mathrm{LH}$ and prolactin during the oestrous cycle observed in the present study for regulation of ovarian function in the sow has not been defined, but experimental hypo- and hyper-prolactinaemia in sows both lead to inverse changes in the secretion of $\mathrm{LH}$ in the sow (Szafranska and Ziecik, 1990; Szafranska and Tilton, 1993), indicating that there are functional interactions in the hypothalamic regulation of $\mathrm{LH}$ and prolactin secretion. These interactions may involve changes in the activity of hypothalamic dopaminergic pathways or changes in the sensitivity to steroids of opiodergic mechanisms, since these pathways result in inverse changes in secretion of the two hormones (Kraeling and Barb, 1990; Willis et al., 1996). Positive evidence for the involvement of such mechanisms remains to be provided. Whatever the mechanisms involved, it seems likely that the seasonal changes in the relative concentrations of $\mathrm{LH}$ and prolactin are indicative of changes in hypothalamic regulatory mechanisms predisposing sows to the onset of anoestrus.

The characteristics of the seasonal anoestrus observed in all untreated control sows during Expt 2, as well as that seen in two control sows during Expt 1, differ little from those of the seasonal anoestrus observed by Delcroix et al. (1990) in wild boar (Sus scrofa) females kept in the absence of boars, and resumption of the oestrous cycle in sows in the present study was consistent with the timing of the onset of the breeding season in female wild boars (Mauget, 1982). It is less apparent why such overt expression of seasonality should occur so infrequently in domestic sows. Inherent differences among sows, resulting from differences in breed, selection criteria for inclusion in experiments or environment and husbandry before the start of the studies, may have influenced expression of this seasonal characteristic. For example, it may be important that sows for Expt 2 were kept at Wytham without any boar contact after selection during the autumn of the previous year. By contrast, sows used in Expt 1 were brought to Wytham just before the start of the study. Some of these sows had been in close contact with boars until this time. The presence of boars masks much of the inhibitory effect of increasing daylength during early summer on attainment of puberty in gilts (Paterson and Pearce, 1990; Paterson et al., 1991) and pheromonal cues from boars are known to play an important role in maintenance of regular oestrous cycles in sows (Booth and Signoret, 1992). Indeed, Booth and Baldwin (1983) showed that postpubertal pigs exhibited prolonged seasonal anoestrus after olfactory bulbectomy, despite being housed with boars. The seasonal anoestrus observed was similar to that observed in intact control sows during the present study. The remarkable degree of synchronization in the return of control sows to oestrous cyclic activity during early November in Expt 2 indicates that significant interactions also occur among females when males are absent. Pearce and Pearce (1992) demonstrated that contact of domestic sows with an oestrus sow was as effective as daily contact with an intact boar in stimulating oestrus after weaning, and concluded that this effect probably also depended on production of pheromones at oestrus.

The possibility that female anoestrus is explained by inadequate male pheromonal stimulation receives support from observations in other species. Robinson et al. (1991) showed that exposure of ewes to an oestrous ewe and a vasectomized ram advanced the start of the breeding season in Scottish Blackface ewes almost as much as melatonin treatment, and that these effects appeared to be additive. Flores et al. (2000) showed that sexually inactive male goats kept under natural photoperiod were unable to induce sexual activity in females, whereas sexually active males, subjected to a period of long days and then given melatonin implants, induced ovulation and oestrus in the females during seasonal anoestrus. In musk shrews (Suncus murinus), olfactory bulbectomy prevents the increase that is normally seen $1 \mathrm{~h}$ after mating in the number of cells in the medial septum-diagonal band of the hypothalamus, which contains proGnRH immunoreactivity and prevents matinginduced ovulation in this species (Rissman and Li, 2000). Olfactory cues are likely to make an important contribution to preservation of regular oestrous cycles in sows by modulating effects on hypothalamic GnRH production. Adverse effects of increasing photoperiod on reproductive hormones, pheromone production and sexual activity in boars (Claus and Weiler, 1985, 1987) may be a primary cause of seasonal anoestrus and summer infertility in sows, just as they appear to be in goats (Flores et al., 2000). The results of the present study provide strong evidence for the existence in sows of seasonal rhythms in plasma concentrations of both $\mathrm{LH}$ and prolactin with a lag between them, so it is possible that the sensitivity of hypothalamic $\mathrm{GnRH}$ release to seasonal regulation is influenced to a significant degree by signals from the olfactory bulb.

Despite prevention of seasonal anoestrus by administration of melatonin implants to some of the sows at, or soon after, the spring equinox, the question of how melatonin may influence their reproduction remains equivocal. The results of the present study provide further support for the view that seasonal rhythms in control of gonadotrophin release underlie adverse changes in sow fertility during the 
summer, but mechanisms by which the underlying rhythm of reproduction is regulated by photoperiodic cues and interacts with olfactory cues from the boar need to be better understood before manipulation of the diurnal melatonin rhythm can be used practically to overcome the problem of seasonal infertility.

The authors acknowledge the invaluable assistance of Ray Borrett, Cliff Hanson, Frances Knight, Stuart Mills, and John Shepherd of the Growth and Development Unit, David Sharpe, Manager of the University Field Station, Sarah Wolfensohn and Maggie Lloyd, University Veterinary Officers and Andrew Stockings, General Manager of Thames Valley Pigs Ltd in the conduct of these investigations. This work was supported financially by contracts with MAFF (CSA1920) and Thames Valley Pigs Ltd. Stephen Goddard and John Pearson of Hoeschst Animal Health Ltd generously provided Regulin ${ }^{\circledR}$ implants and advice on their use. Andrew Foldes of the CSIRO Division of Animal Production, Prospect, NSW, Australia generously provided the 'Prospect' anti-melatonin antiserum. Prolactin and LH antisera and pig standards were provided by A. H. Parlow, Pituitary Hormones and Antisera Center, Harbor-UCLA Medical Center, Torrance, CA under the Hormones and Pituitary Program of the National Institute of Diabetes and Digestive and Kidney Diseases, USA.

\section{References}

Adam CL, Moir CE and Shiach P (1989) Melatonin can induce year-round ovarian cyclicity in red deer (Cervus elaphus) Journal of Reproduction and Fertility $\mathbf{8 7}$ 401-408

Arendt J (1995) Melatonin and the Mammalian Pineal Gland pp110-160 Chapman and Hall, London

Armstrong JD, Britt JH, and Cox NM (1986) Seasonal differences in function of the hypothalamic-hypophysial-ovarian axis in weaned primiparous sows Journal of Reproduction and Fertility $\mathbf{7 8} 11-20$

Bassett JM, Bray CJ and Sharpe CE (1996) Summer infertility in outdoor sows: lessons from studies on 'seasonally barren' sows Pig Journal 36 65-85

Booth WD and Baldwin BA (1983) Changes in oestrous cyclicity following olfactory bulbectomy in post-pubertal pigs Journal of Reproduction and Fertility 67 143-150

Booth WD and Signoret JP (1992) Olfaction and reproduction in ungulates Oxford Reviews in Reproductive Biology 14 263-301

Bray CJ, Sharpe CE and Bassett JM (1994) Detailed analyses of individual sow records from outdoor pig units I. Seasonal variation in the incidence of barren sows. In Programme of the 45th Annual Meeting of the European Association for Animal Production, Edinburgh 1994 p 304 EAAP 1994 Secretariat, Penicuik

Claus R and Weiler U (1985) Influence of light and photoperiodicity on pig prolificacy Journal of Reproduction and Fertility Supplement $\mathbf{3 3}$ 185-197

Claus R and Weiler U (1987) Seasonal variation of fertility in the pig and its explanation through hormonal profiles. In Definition of the Summer Infertility Problem in the Pig pp 127-139 Eds E Seren and M Mattioli. Commission of the European Communities, Brussels

Claus R, Hoaung-Vu C and Weiler R (1987) Seasonal variation of the ovarian function in unmated sows revealed by the measurement of progesterone and 17- $\beta$ oestradiol in peripheral blood plasma Journal of Veterinary Medicine A 34 344-352

Delcroix I, Mauget R and Signoret JP (1990) Existence of synchronization of reproduction at the level of the social group of the European Wild Boar (Sus scrofa) Journal of Reproduction and Fertility 89 613-617

Diekman MA, Clapper JA, Green ML and Stouffer DK (1991a) Reduction in age of puberty in gilts consuming melatonin during decreasing or increasing daylengths Journal of Animal Science $692524-2531$
Diekman MA, Green ML, Fears TE, Malayer JR and Kuczek T (1991b) Effect of sampling interval on serum concentrations of luteinizing hormone, follicle stimulating-hormone and prolactin in prepubertal, ovariectomized and cycling gilts Biology of Reproduction 45 755-763

Flores JA, Véliz FG, Pérez-Villanueva JA, Martinez de la Escalera G, Chemineau P, Poindron P, Malpaux B and Delgadillo JA (2000) Male reproductive condition is the limiting factor of efficiency in the male effect during seasonal anoestrus in female goats Biology of Reproduction 62 1409-1414

Fraser S, Cowen P, Franklin M, Franey C and Arendt J (1983) Direct radioimmunoassay for melatonin in plasma Clinical Chemistry 29 396-397

Karsch FJ, Robinson JE, Woodfill CJI and Brown MB (1989) Circannual cycles of luteinizing hormone and prolactin secretion in ewes during prolonged exposure to a fixed photoperiod: evidence for an endogenous reproductive rhythm Biology of Reproduction 41 1034-1046

Kennaway DJ and Seamark RF (1980) Circulating levels of melatonin following its oral administration or subcutaneous injection in sheep and goats Australian Journal of Biological Science 33 349-353

Kermabon AY, Prunier A, Dijane J and Salesse R (1995) Gonadotropins in lactating sows exposed to long or short days during pregnancy and lactation: serum concentrations and ovarian receptors Biology of Reproduction 53 1095-1102

Klupiec C, Evans G, Love RJ and Kennaway DJ (1997) Clarifying plasma melatonin profiles in domestic pigs: a critical and comparative evaluation of two radioimmunoassay systems Journal of Pineal Research 22 65-74

Kraeling RR and Barb CR (1990) Hypothalamic control of gonadotrophin and prolactin secretion in pigs Journal of Reproduction and Fertility Supplement 40 3-17

Love RJ, Evans G and Klupiec C (1993) Seasonal effects on fertility in gilts and sows Journal of Reproduction and Fertility Supplement 48 191-206

Lincoln GA and Clarke IJ (1994) Photoperiodically induced cycles in the secretion of prolactin in hypothalamo-pituitary disconnected rams. Evidence for translation of the melatonin signal in the pituitary gland Journal of Neuroendocrinology 6 251-260

Malpaux B, Wayne NL and Karsch FJ (1988) Termination of the breeding season in the Suffolk ewe: involvement of an endogenous rhythm of reproduction Biology of Reproduction 39 254-263

Mauget R (1982) Seasonality of reproduction in the wild boar. In Control of Pig Reproduction pp 509-526 Eds DJA Cole and GR Foxcroft. Butterworth, London

Mauget R (1985) Seasonal anoestrus in wild sows. In Endocrine Causes of Seasonal and Lactational Anoestrus in Farm Animals pp 108-118 Eds F Ellendorff and F Elsaesser. Martinus Nijhoff, Dordrecht

O'Callaghan D, Karsch FJ, Boland MP and Roche JF (1991) What photoperiodic signal is provided by a continuous-release melatonin implant? Biology of Reproduction 45 927-933

Paterson AM and Foldes A (1994) Melatonin and farm animals: endogenous rhythms and exogenous applications Journal of Pineal Research $\mathbf{1 6}$ $167-177$

Paterson AM and Pearce GP (1990) Attainment of puberty in domestic gilts reared under long-day or short-day artificial light regimens Animal Reproduction Science 23 135-144

Paterson AM, Pearce GP and D'Antuono MF (1991) Seasonal variation in attainment of puberty in isolated and boar-exposed domestic gilts Animal Reproduction Science 24 323-333

Paterson AM, Martin GB, Foldes A, Maxwell CA and Pearce GP (1992a) Concentrations of plasma melatonin and luteinizing hormone in domestic gilts reared under artificial long or short days Journal of Reproduction and Fertility 94 85-95

Paterson AM, Maxwell CA and Foldes A (1992b) Seasonal inhibition of puberty in domestic gilts is overcome by melatonin administered orally, but not by implant Journal of Reproduction and Fertility 94 97-105

Peacock AJ (1991) Environmental and Social Factors Affecting Seasonal Infertility of Pigs PhD Thesis, University of Sydney

Pearce GP and Pearce AN (1992) Contact with a sow in oestrus or a mature boar stimulates the onset of oestrus in weaned sows Veterinary Record 130 5-9 
Poulton AL, English J, Symons AM and Arendt J (1986) Effects of various melatonin treatments on plasma prolactin concentrations in the ewe Journal of Endocrinology 108 287-292

Ravault JP, Martinat-Botte F, Mauget R, Martinat N, Locatelli A and Bariteau $\mathbf{F}$ (1982) Influence of daylight on prolactin secretion in the pig: hourly rhythm in ovariectomized females, monthly variation in domestic (male and female) and wild strains during the year Biology of Reproduction 27 1084-1089

Reiter RJ, Britt JH and Armstrong JD (1987) Absence of a nocturnal rise in either norepinephrine, $\mathrm{N}$-acetyltransferase, hydroxyindole $\mathrm{O}$-methyltransferase, or melatonin in the pineal gland of the domestic pig under natural environment photoperiods Neuroscience Letters 81 171-176

Rissman EF and Li X (2000) Olfactory bulbectomy blocks mating-induced ovulation in musk shrews (Suncus murinus) Biology of Reproduction 62 1052-1058

Robinson JJ, Wigzell S, Aitken RP, Wallace JM, Ireland S and Robertson SS (1991) The modifying effects of melatonin, ram exposure and plane of nutrition on the onset of ovarian activity, ovulation rate and the endocrine status of ewes Animal Reproduction Science 26 73-91

Smith CA and Ficken MD (1991) Non-surgical cannulation of the vena cava for chronic blood collection in mature swine Laboratory Animal Science $41274-278$

Staples LD, McPhee JR and Williams AH (1991) Practical applications for controlled release melatonin implants in sheep Advances in Pineal Research 6 199-208
Szafranska B and Tilton JE (1993) Prolactin as a luteotrophin during pregnancy in pigs Journal of Reproduction and Fertility 98 643-648

Szafranska B and Ziecik AJ (1990) Effect of bromocriptine administration on maintenance of late pregnancy in the pig Experimental and Clinical Endocrinology $96321-324$

Williams LM, Hannah LT and Bassett JM (1999) Melatonin receptors in neonatal pig brain and pituitary gland Journal of Pineal Research 26 43-49

Willis HJ, Cosgrove JR and Foxcroft GR (1996) Opiodergic control of luteinizing hormone and prolactin secretion in late gestation in the sow Biology of Reproduction 55 318-324

Woodfill CJI, Wayne NL, Moenter SM and Karsch FJ (1994) Photoperiodic synchronization of a circannual reproductive rhythm in sheep: identification of season-specific time cues Biology of Reproduction $\mathbf{5 0}$ 965-976

Wyrzykowski Z, Przybylska B, Wyrzykowska K, Karasek E and Karasek M (1989) Circadian plasma melatonin profile in the sexually immature female domestic pig Neuroendocrinology Letters 11 201-206

Received 9 August 1999.

First decision 24 September 1999.

Manuscript resubmitted 3 October 2000.

Accepted 30 November 2000. 